\title{
Reformulação de cursos de licenciatura na Bahia: interesses e desafios subjacentes
}

DOI https://10.31639/rbpfp.v\%vi\%i.226

\author{
Arlete Ramos Santos \\ Universidade Estadual do Sudoeste da Bahia (UESB), Bahia-Brasil \\ http://orcid.org/0000-0003-0217-3805 \\ Elisângela Andrade Moreira Cardoso \\ Universidade Estadual do Sudoeste da Bahia (UESB), Bahia-Brasil \\ http://orcid.org/0000-0001-9581-0644 \\ Claudio Pinto Nunes \\ Universidade Estadual do Sudoeste da Bahia (UESB), Bahia - Brasil \\ http://orcid.org/0000-0003-1514-6961
}

\begin{abstract}
RESUMO: Este artigo traz os resultados de uma pesquisa que teve como objetivo investigar os principais desafios enfrentados por três Instituições de Ensino Superior - IES da Bahia, para reformular os cursos de licenciatura, com destaque para o curso de Pedagogia. Trata-se de uma pesquisa qualitativa, de natureza exploratória, cujos dados foram coletados por meio de entrevistas semiestruturadas, realizadas com coordenadores e docentes do referido curso. Os resultados demonstraram que as reformulações foram realizadas a partir da influência das agências internacionais que exigem a elaboração de políticas educacionais de formação docente e adequação curricular nas licenciaturas para atender o mercado. Mas também, merecem atenção a falta de interesse dos alunos pelas licenciaturas devido à falta de garantia de retorno financeiro, além das condições sociais e econômicas desfavoráveis de grande parte desses discentes que necessitam de um olhar das políticas públicas para garantir o acesso e permanência para concluírem a formação inicial.
\end{abstract}

PALAVRAS-CHAVE: Formação inicial. Política educacional. Reformulação.

\section{Reformulation on the teaching license programs in Bahia: interests and underlying challenges}

\begin{abstract}
This article brings the results of a research that had as objective to investigate the main challenges faced by three Higher Education Institutions - IES of Bahia, to reformulate the Teaching License Programs, with emphasis on the Pedagogy course. It is a qualitative research, of exploratory nature, whose data were collected through semi-structured interviews, carried out with coordinators and teachers of this course. The results showed that the reformulations were carried out from the influence of the international agencies that require the elaboration of educational policies of teacher education and curricular adequacy in the degrees to attend the market. However, it is necessary to observe the students' lack of interest in the degree programs due to the lack of guarantee of financial return, in addition to the unfavorable social and economic conditions of a large number of those students who need a look at public policies to guarantee their access and permanence to conclude the initial training.
\end{abstract}

KEYWORDS: Initial training. Educational politics; Reformulation. 


\section{Reformulación de cursos de licenciatura en Bahia: intereses y desafíos subjacentes}

RESUMEN: Este artículo trae los resultados de una investigación que tuvo como objetivo investigar los principales desafíos enfrentados por tres Instituciones de Enseñanza Superior - IES de Bahía, para reformular los cursos de licenciatura, con destaque para el curso de Pedagogía. Se trata de una investigación cualitativa, de naturaleza exploratoria, cuyos datos fueron recolectados por medio de entrevistas semiestructuradas, realizadas con coordinadores y docentes del dicho curso. Los resultados demostraron que las reformulaciones se realizaron a partir de la influencia de las agencias internacionales que exigen la elaboración de políticas educativas de formación docente y adecuación curricular en las licenciaturas para atender el mercado. Pero también merecen atención la falta de interés de los alumnos por las licenciaturas debido a la falta de garantía de retorno financiero, además de las condiciones sociales y económicas desfavorables de gran parte de esos discentes que necesitan una mirada de las políticas públicas para garantizar el acceso y permanencia para que concluyan la formación inicial.

PALABRAS CLAVE: Formación inicial. Política educativa. Reformulación. 


\section{INTRODUÇÃO}

As ações desenvolvidas pelo Estado brasileiro perpassam pelas políticas públicas que envolvem as esferas federal, estaduais e municipais, e estas ações têm por finalidade o atendimento das demandas dos diversos setores sociais por meio de recursos que se desdobram nas políticas sociais e educacionais. No que diz respeito às políticas sociais, estas se voltam para a formulação, avaliação e execução dos programas constituídos pelo sistema econômico capitalista e, de acordo com Pereira (2008), estas políticas objetivam acatar as necessidades sociais que estão além da iniciativa privada, individual e espontânea, como forma de justiça social. Quanto às políticas educacionais, estas são direcionadas para as leis, os regulamentos, pareceres e decretos sobre a educação, constituídos pela colisão entre o Estado e a sociedade civil, e são alteradas de acordo com o contexto político, econômico e social de cada país.

Estudar a forma como a relação de forças antagônicas para o fortalecimento dessas políticas que sustentam o capitalismo se movimentam é uma necessidade premente no meio acadêmico, e é o que deve ser feito por meio de pesquisas e estudos que nos façam compreender os fenômenos que estão subjacentes às contradições do capital. Nas Instituições de Ensino Superior - IES, as adequações da política educacional ao realinhamento dos interesses do capitalismo globalizado têm se concretizado nas reformulações curriculares, principalmente, em cursos de formação de professores, pois são os docentes que estarão em cena implementando um projeto educacional que possa confirmar o modelo societal que esteja de acordo com os interesses do capital ou do trabalho.

Para compreender esse cenário, realizamos uma pesquisa que originou este texto, a qual teve como objetivo analisar quais os principais desafios enfrentados para a reformulação dos cursos de licenciatura, com destaque para o curso de Pedagogia, em três IES estaduais baianas, sendo duas universidades públicas e uma privada. O texto está dividido em três partes. A primeira delas traz uma arcabouço teórico que nos faz compreender como as políticas educacionais estão inseridas no capitalismo globalizado; a segunda, se reporta para a formação inicial de professores no contexto brasileiro, e como a mesma está inserida nas políticas educacionais vigentes; e por fim, a última parte que apresenta os dados da pesquisa, destacando, inicialmente, os resultados obtidos nas IES públicas, seguidos dos que foram coletados na IES privada. Salientamos que devido aos limites de espaço nesse texto, não fazemos uma análise teórica aprofundada dos dados.

\section{BREVE EXPLANAÇÃO DA FORMAÇÃO DE PROFESSORES NA POLÍTICA EDUCACIONAL BRASILEIRA ${ }^{1}$}

A política de formação de professores é uma construção recente no cenário das políticas educacionais brasileiras e, a trilogia estabelecida entre Estado, políticas educacionais e instituições escolares se constituiu como um modelo de regulação e reforço com realidades contrapostas demarcadas pela divisão social de classes, visto que o conceito de política está em conexão com o Estado moderno capitalista.

Para Marx e Engles (1981), o Estado capitalista decorre da inópia mediação entre o conflito sucedido das classes e a manutenção da ordem que reproduz a burguesia. Dessa forma, o Estado Burguês recorre às empresas para realizar a "governança", cujo Estado tem como finalidade assegurar os interesses das classes dominantes, garantindo assim, a ordem social, bem como as relações de produção e a acumulação do capital. As ferramentas necessárias para tratar algumas das dificuldades sociais foram abaladas e destruídas pela

1 A $1^{\text {a }}$ parte do texto traz um recorte da Dissertação de Mestrado de Elisângela Andrade Moreira Cardoso, defendida em 2018 no Programa de Pós-Graduação em Educação da Universidade Estadual do Sudoeste da Bahia (PPGed/Uesb). 
força do Estado, o qual tem como foco eternizar o domínio do capital, em meio ao conformismo ideológico e a imposição política. (MÉSZÁROS, 2014).

As políticas públicas educacionais brasileiras tiveram destaque na década de 1990 em meio às formulações, implantações e parcerias estabelecidas pelo governo federal e os entes federados que favoreceram não apenas a descentralização, mas também a privatização e a flexibilização da educação nacional, cujas diretrizes foram acasteladas por organismos internacionais voltados para os interesses da burguesia hegemônica, como o Fundo Monetário Internacional (FMI), o Banco Mundial e a Organização das Nações Unidas para Educação, Ciência e Cultura (Unesco).

A articulação entre os organismos e o sistema capitalista propiciou a doutrina neoliberal, ligando os princípios da desregulamentação econômica, a intervenção mínima estatal, privatização, competitividade e a aquisição do lucro, entre outras evidências que repercutem na formulação de políticas públicas de cunho social, principalmente na educação.

De acordo com Silva e Sanfelice (2008), o neoliberalismo

[...] tem resultado em duas perspectivas no campo da formação profissional dos educadores: o aligeiramento e a precarização na formação dos professores para educação básica e a desvalorização e a proletarização da carreira docente como um todo, levando a uma supervalorização dos conhecimentos elaborados pelos especialistas e pelo conhecimento específico da área de formação, relegando ao segundo plano os conhecimentos pedagógicos. (SILVA; SANFELICE, 2008, p. 36).

Desse modo, a educação brasileira passou a ser alvo dos interesses empresariais privatistas e da classe hegemônica, sendo materializada pelas legislações que regem o país, como a Constituição Federal Brasileira de 1988, a Lei de Diretrizes e Bases da Educação Nacional (LDB) n 9.394, de 1996a, a Emenda Constitucional no 14 de 1996b e o Plano de Desenvolvimento da Educação (PDE). De acordo com Saviani (2007, p. 3), estas Leis são o "carro-chefe do Plano de Metas Compromisso Todos pela Educação".

Nessa perspectiva, o MEC assegura que a Política de Formação de Professores é definida como um processo que leva em consideração articulações entre as esferas Federal, Estadual e Municipal. Porém, nota-se que as ações desta Política estão profundamente atreladas ao Plano de Metas da Educação, mais precisamente ao PDE que foi exposto pelo MEC em abril de 2007, por meio do qual o referido Ministério disponibilizou instrumentos para avaliação e implementação de políticas que visem à melhoria da qualidade da educação, principalmente, da Educação Básica do sistema público, para o Distrito Federal, os estados e municípios. A partir de então, as transferências voluntárias e a assistência técnica do MEC para estes entes federados estão vinculadas à adesão ao Plano de Metas, intitulado "Compromisso Todos pela Educação" e à elaboração do Plano de Ações Articuladas (PAR), que são ferramentas essenciais para a melhoria do Índice de Desenvolvimento da Educação Básica (ldeb), cuja preocupação consiste em que os alunos da Educação Básica respondam questões relacionadas às áreas do conhecimento, demonstrando um perfil de "cidadão" voltado para o consumo e o mercado de trabalho.

Em meio a estas políticas educacionais, o MEC desenvolveu alguns Programas educacionais para a formação dos professores, como: o Proformação em 1997; a Rede Nacional de Formação Continuada de Professores (Renafor) em 2004; o Programa de Formação Inicial para os Professores em Exercício na Educação Infantil (Proinfantil), também em 2004; o Programa de Formação Inicial para Professores dos Ensinos Fundamental e 
Médio (Prolicenciatura) em 2005; o Programa de Formação Continuada de Professores que atuam nos Anos/ Séries Iniciais do Ensino Fundamental (Proletramento) em 2006; o Plano Nacional de Formação de Professores da Educação Básica (Parfor) em 2009; e o Pacto Nacional pela Alfabetização na Idade Certa (Pnaic) em 2012.

De acordo com Arelaro (2007), apesar das estratégias lançadas pelo empresariado brasileiro para gerir o ensino no país, por meio dos recursos públicos, estas não oferecem condições que possam garantir a tão propalada "qualidade na educação" e acarretam conceitos contraditórios quanto à eficiência educacional. Nesse contexto, em 2007 surge o Plano de Ações Articuladas (PAR) coligado ao Plano de Desenvolvimento da Educação (PDE), sob o regime de colaboração com os Municípios com o propósito de alcançar melhores resultados por meio de suas dimensões, bem como superar as visíveis desigualdades pertencentes ao sistema educacional, sendo, portanto, um instrumento relevante de fiscalização, validação de ações, monitoramento de resultados e articulação das propostas de políticas públicas em âmbito nacional e em regime de colaboração com os Municípios. (OLIVEIRA, 2002).

Todavia, esse texto tem como foco a Dimensão 2 do PAR, a qual trata especificamente da Formação de Professores, de Profissionais de Serviços e de Apoio Escolar e, para atender às necessidades explícitas nas Dimensões do PAR, o Governo brasileiro oferece vários programas educacionais aos municípios que são disponibilizados pelo Sistema Integrado de Monitoramento Execução e Controle do Ministério da Educação (Simec). Esse Sistema reúne ações que disponibilizam recursos para os municípios quanto à gestão democrática, a formação inicial e continuada, bem como a educação inclusiva e a capacitação para o pessoal de apoio, entre outras, obedecendo ao princípio basilar do diagnóstico preenchido no Simec para os sistemas educativos municipais. (SANTOS; OLIVEIRA; CARDOSO, 2017).

No entanto, alguns pesquisadores da educação acreditam que este Plano é mais um instrumento de centralização que o Governo Federal constitui por meio do Fundo Nacional de Desenvolvimento da Educação (FNDE). Quanto ao PDE, observamos que há transferência de responsabilidade do Estado aos distintos setores da sociedade civil, como o setor privado que assume a política educacional em meio às parcerias, sobretudo, entre as prefeituras e o setor empresarial, conforme assegura Barão (2009). Nesse viés, o PDE se articula com o Plano de Metas do Compromisso Todos pela Educação e se estabelece como uma política educacional favorável à classe dominante, a qual é implementada em conformidade com os padrões do Banco Mundial. (SANTOS; CARDOSO, 2017).

De acordo com as autoras supracitadas (2017, p. 07),

Nesse cenário, encontram-se as universidades com o desafio de formar professores com conhecimentos acadêmicos, compromisso político com vistas nas transformações educacionais e sociais, bem como a adequação às novas tecnologias e, sobretudo, a aplicabilidade dos conhecimentos adquiridos no processo de formação dos educandos em meio às provocações da sociedade contemporânea, constituída por distintos padrões, métodos e práticas educativas.

Como cumprimento da Diretriz XII do Plano de Metas, em 2009 o Governo Federal instituiu o Decreto ${ }^{\circ}$ 6.755/2009, ora revogado pelo Decreto n 8.752/2016, a Política Nacional de Formação de Profissionais do Magistério da Educação Básica (Parfor) e disciplina a atuação da Coordenação de Aperfeiçoamento de Pessoal de Nível Superior (Capes) no fomento a programas de formação inicial e continuada. (BRASIL, 2009).

Saviani (2006) acredita que a educação tem apresentado mudanças históricas, que ao trabalho docente era atribuído valor de sacerdócio e que o ensino era uma doutrina considerada como a única verdade. No cerne 
das discussões acerca das políticas públicas educacionais no cenário brasileiro, consideramos que as ações dessas políticas perpassam por caminhos despreocupados com os reais problemas e necessidades urgentes da população, em meio a atuações imediatistas que estão aquém das transformações imperativas que causam descrença e descredibilidade em toda a sociedade.

Propalados como resultados os Dados do Educacenso de 2015, observa-se um avanço significativo em meio ao cruzamento de dados informados pelo Instituto Nacional de Estudos e Pesquisas Educacionais Anísio Teixeira (Inep) acerca do Censo da Educação Básica e o Censo da Educação Superior. Diante desse fato, foi possível diagnosticar que muitos profissionais que atuam no Magistério da Educação Básica, também são alunos da Educação Superior. Isso evidencia que o processo de melhoria da qualificação desses profissionais está em pleno curso no cenário brasileiro. (INEP, 2015a, 2015b).

No entanto, não podemos negar que mesmo com os entraves nas políticas de formação para professores, o avanço na qualidade da formação superior no país ocorre por meio dos Programas e pelo esforço dos próprios professores na busca de preparo para o exercício da profissão, os quais tentam conciliar na medida do possível, seus respectivos horárias de trabalho às suas formações, sem se afastarem de suas funções.

\section{DISCUTINDO A FORMAÇÃO INICIAL DE PROFESSORES}

A Política Nacional de Formação de Profissionais do Magistério da Educação Básica (BRASIL, 2009) pode ser considerada como uma alternativa para a correção dos desvios pertinentes à formação docente ao buscar dirimir as desigualdades dessa área, baseando-se, sobretudo, nos princípios da "articulação entre a teoria e a prática no processo de formação docente", na "importância do projeto formativo, assegurando organicidade ao trabalho e garantindo sólida base teórica e interdisciplinar" e na "importância do docente no processo educativo da escola e de sua valorização profissional, traduzida em políticas permanentes de estímulo à profissionalização", entre outros (BRASIL, 2009, Artigo 2\%).

Ademais, diante das demandas impostas ao sistema educacional, novas exigências surgem na perspectiva de integrar os professores aos mais distintos paradigmas propulsores do desenvolvimento que são imbricados ora pelas propostas tecnológicas, ora pela apreensão e produção do conhecimento.

No Brasil, a Formação de Professores da Educação Básica é normatizada pela organização de documentos legais que se articulam para dar sustentação a uma política nacional que almeja não apenas a formação inicial mínima para o exercício do Magistério nos diferentes níveis e modalidades da educação e do ensino, mas também a promoção da formação continuada para os profissionais do Magistério da Educação Básica, numa conjectura que caminha rumo à "equalização de oportunidades educacionais e padrão mínimo de qualidade do ensino" (BRASIL, 1988).

O Artigo 211 presente na Constituição de 1988 assegura que:

A União, os Estados, o Distrito Federal e os Municípios organizarão em regime de colaboração seus sistemas de ensino. (EMENDA CONSTITUCIONAL N 14/96 E EMENDA CONSTITUCIONAL $\left.N^{\circ} 53 / 2006\right)$

$\S 1^{\circ} \mathrm{A}$ União organizará o sistema federal de ensino e o dos Territórios, financiará as instituições de ensino públicas federais e exercerá, em matéria educacional, função e distributiva e supletiva, de forma a garantir equalização de oportunidades educacionais e padrão mínimo de qualidade do ensino mediante assistência técnica e Financeira aos Estados, ao Distrito Federal e aos Municípios. (BRASIL, 1988). 
Nota-se, portanto, que a referida Constituição Federal favorece a formação inicial docente, sobretudo, inicial de muitos profissionais da educação em exercício, por isso, a LDB n 9.394/96, destaca também a exigência da formação em nível superior, para que os profissionais da educação possam exercer a docência. Destarte, as políticas educacionais voltadas para a formação de professores estão atreladas à ideologia neoliberal, fomentadas por movimentos que envolvem tensões, equívocos e desafios. E, ante a reestruturação do capitalismo nos cenários internacional e global econômicos, as políticas e programas de formação de professores emergiram por toda a nação brasileira, visando, principalmente, atender aos interesses do capital. (FREITAS, 2007).

As políticas de formação de professores foram alavancadas em 2015 por meio das novas Diretrizes Curriculares Nacionais para a Formação Inicial e Continuada dos Profissionais do Magistério da Educação Básica, em conformidade com o Parecer CNE/CP nº 02/2015 (BRASIL, 2015a) e a Resolução CNE/CP nº 02/2015. (BRASIL, 2015b).

Essas Diretrizes têm como finalidade garantir a organização da formação inicial e continuada desses profissionais e, corroborando com essas ideias, Dourado (2015) as definem como "princípios da formação inicial e continuada dos professores da educação básica e sinalizam para maior organicidade nos projetos formativos e maior articulação entre a educação superior e a educação básica" (DOURADO, 2015, p. 306).

As Diretrizes apontam que a formação de professores deve ser não apenas constituída, mas também desenvolvida pela articulação entre as IES, os sistemas de ensino e as unidades escolares da Educação Básica, obedecendo ao regime de colaboração e cooperação entre os entes federados. Assim, o direito à educação é garantido àqueles que se encontram excluídos do processo social histórico e, inúmeras transformações se firmam nas IES e na Educação Básica, visando melhorar a formação dos professores.

Em 2016, mais precisamente no dia 9 de maio, instituiu-se o Decreto $n^{\circ}$ 8.752, revogando e substituindo o de $n^{\circ}$ 6.755/09, no qual, de acordo com o Art. $1^{\circ}$, regulamenta a Política Nacional de Formação dos Profissionais da Educação Básica, fixa os princípios e objetivos, além de apresentar a organização dos programas e suas ações, em colaboração com os sistemas de ensino, o Plano Nacional de Educação e os planos decenais pertencentes aos Estados, ao Distrito Federal e os Municípios. (BRASIL, 2016).

Em consonância com esse Decreto, a política de formação de professores passa a ser acaudilhada pelo "Planejamento Estratégico Nacional", que é deliberado pelo MEC, consagrado e supervisionado pelo "Comitê Gestor Nacional", formado pelos Fóruns Estaduais e Distrital, com o intuito de apoiar a formação dos profissionais da educação e estabelecer a centralização e a regulação das políticas de formação. Assim, o Comitê é visto como um processo basilar capaz de redigir o plano estratégico nas respectivas unidades federativas.

Enquanto este novo Decreto se caracteriza pelo avanço ao reconhecer como lócus de formação as instituições educacionais, bem como, a importância de se articular teoria e prática para a valorização do docente e a carência de firmar parcerias entre pesquisadores acadêmicos e professores, uma vez que a elaboração coletiva do conhecimento reverbera no desenvolvimento promissor do trabalho desse profissional, também se define por sua legitimação a um processo atrasado, ao aceitar, profissionais que tenham apenas o Ensino Médio, também chamado de Normal, para atuarem como professores da Educação Básica.

A discussão acerca da formação do professor nos remete aos achados dos teóricos Libâneo e Pimenta (1999, p. 22), os quais afirmavam que "não é qualquer um que pode ser professor", haja vista que o professor está 
em constante formação. Nesse cenário, os profissionais da educação, verdadeiros protagonistas desse embate, buscam, dentro das suas possibilidades, "compreender as ocorrências e os desfechos para tantas mazelas sociais e, através de suas ações reforçam suas práticas e contribuem para o desenvolvimento das habilidades e competências de seus educandos, no tocante ao processo de ensino e aprendizagem" (CARDOSO; NUNES, 2017).

Apesar disso, as transformações sociais que decorrem do processo de globalização têm proporcionado ao professor uma formação mais desafiadora que se volta constantemente para a necessidade de atualização de saberes e a habilitação adequada dos profissionais. Nessa perspectiva, as Universidades têm o desafio de acompanhar as transformações sociais e o desenvolvimento tecnológico, sobretudo, nos cursos de Licenciatura, com o intuito de formar professores mais eficientes e preparados para o mundo social do trabalho, que se mostra cada vez mais exigente. $E$, frente às questões concernentes à adequação do tempo, do espaço e dos movimentos sociais emergentes, Cardoso e Nunes (2017) asseguram que "as IES, por conhecerem as legislações educacionais, disponibilizaram mais cursos com a finalidade de formar professores que respondessem aos desafios sociais contemporâneos e, pela demanda da profissão docente, o foco da oferta tornou-se mais acentuado e a procura concentrou-se nos cursos de Pedagogia". E é no intuito de atualizar os cursos de licenciatura em consonância com as novas diretrizes, decretos e resoluções para formar os docentes que vem acontecendo nas IES, a reformulação dos cursos de licenciatura.

\section{DESAFIOS PARA OS CURSOS DE LICENCIATURA NOS ACHADOS DA PESQUISA}

A formação de professores no Brasil, até o final do século XIX, acontecia nas escolas normais, em cursos específicos, denominados de "primeiras letras". Entretanto, estas escolas continuaram responsáveis pela formação de professores para os anos iniciais do ensino fundamental até o advento da LDB n 9.394/96, por meio da qual ficou definido que todos os professores deveriam ter curso superior em até uma década. Retrocedendo um pouco na história, observamos que a partir de 1930, surgiu uma preocupação com a formação docente para o nível secundário. Naquela ocasião, os bacharéis poderiam optar em estudar mais um ano na faculdade, para cursar disciplinas da área de educação com o intuito de adquirir a licenciatura, e assim, ficar habilitado para dar aulas. Esse modelo conhecido como " $3+1$ " também passou a ser utilizado nos cursos de Pedagogia que à época formavam os especialistas em educação. Porém, em 1986, o Parecer $n^{\circ} 161$, do Conselho Federal de Educação, reformula o referido curso, para que o mesmo pudesse atuar na oferta de formação para a docência de $1^{\mathrm{a}}$ a $4^{\mathrm{a}}$ séries do ensino fundamental. Mas Gatti salienta que

\footnotetext{
Quanto aos cursos de graduação em Pedagogia, somente em 2006, depois de muitos debates, o Conselho Nacional de Educação aprovou a Resolução n. 1, de 15/05/2006, com as Diretrizes Curriculares Nacionais para esses cursos, propondo-os como licenciatura e atribuindo a estes a formação de professores para a educação infantil e anos iniciais do ensino fundamental, bem como para o ensino médio na modalidade Normal, onde fosse necessário e onde esses cursos existissem, e para a educação de jovens e adultos, além da formação de gestores (2010, p. 1357).
}

Todavia, foram várias as atribuições destinadas ao pedagogo por meio dessa Resolução CNE/CP $n^{\circ} 1$, de 15 de maio de 2006, e, por isso, houve a criação de muitas disciplinas para dar conta do que estava expresso na legislação, causando problemas em função da duração do curso e da carga horária necessária para formar um profissional com capacidade para "a aplicação ao campo da educação, de contribuições, entre outras, de conhecimentos como o filosófico, o histórico, o antropológico, o ambiental-ecológico, o psicológico, o linguístico, o sociológico, o político, o econômico, o cultural" (Art. $2^{\circ}$, BRASIL, 2006). Além disso, no Art. $4^{\circ}$ da mesma 
resolução diz que a formação para o pedagogo deve "englobar a formação de habilidades de planejamento, execução, coordenação, acompanhamento e avaliação de tarefas próprias do setor da Educação, de projetos e experiências educativas não escolares" (BRASIL, 2006). São vários artigos, trazendo muitas atribuições para esse profissional, o que redundou em questionamentos, e o surgimento das outras legislações futuras, citadas anteriormente, que versam sobre a formação de professor, e que a partir destas, surge a necessidade de reformulação dos cursos de licenciatura, os quais, pela legislação vigente, têm por objetivo formar professores para atuar na educação básica e suas modalidades. Nesse sentido, o PNE destaca na sua Meta 15.6:

15.6) promover a reforma curricular dos cursos de licenciatura e estimular a renovação pedagógica, de forma a assegurar o foco no aprendizado do (a) aluno (a), dividindo a carga horária em formação geral, formação na área do saber e didática específica e incorporando as modernas tecnologias de informação e comunicação, em articulação com a base nacional comum dos currículos da educação básica, de que tratam as estratégias 2.1, 2.2, 3.2 e 3.3 deste PNE (BRASIL, 2014).

Para dar esse encaminhamento, algumas dificuldades são encontradas pelas IES, principalmente no que se refere ao modelo econômico (projeto do capitalismo neoliberal) vigente e, nessa esteira, as reformas educacionais sobre a reestruturação produtiva no país. Da convergência dos interesses econômicos, iniciados com a Conferência Mundial sobre Educação para Todos (1990) e dos documentos que daí decorreram, sobretudo dos objetivos aludidos no Plano Diretor da Reforma do Aparelho do Estado (BRESSER PEREIRA, 1995). Na atualidade, o ápice desses desafios são organizados na BNCC, bem como na ampliação pela CAPES/MEC dos cursos de licenciatura na modalidade $\mathrm{EaD}$ e no investimento robusto na educação superior privada, por meio do Fundo de Financiamento Estudantil - FIES e Programa Universidade para Todos - PROUni. Na atualidade, a existência das licenciaturas (modalidade presencial) está ameaçada, diante do enfrentamento do conjunto de decisões políticas adotadas pelo país, as quais foram tecidas ao longo do tempo pelo capital, pelo projeto neoliberal e contra a educação para a emancipação política, econômica, reflexiva da pessoa.

Somam-se a estes aspectos uma conjunção de outros fatores já apontados por Gatti (2010, p. 5):

[...] as políticas educacionais postas em ação, o financiamento da educação básica, aspectos das culturas nacional, regionais e locais, hábitos estruturados, a naturalização em nossa sociedade da situação crítica das aprendizagens efetivas de amplas camadas populares, as formas de estrutura e gestão das escolas, formação dos gestores, as condições sociais e de escolarização de pais e mães de alunos das camadas populacionais menos favorecidas (os "sem voz") e, também, a condição do professorado: sua formação inicial e continuada, os planos de carreira e salário dos docentes da educação básica, as condições de trabalho nas escolas.

Diante dos problemas elencados por Gatti (2010), oriundos pelo modelo de subjunção à lógica do capital, que traz problemas sociais, observamos que há uma complexidade cada vez maior no contexto social, a qual exige mudanças no processo ensino-aprendizagem, e por sua vez, numa formação de professores que possam dar conta das exigências do modelo social que está posto. Nesse sentido, as licenciaturas necessitam se adequar às estruturas institucionais que as abrigam, e também quanto aos seus currículos e conteúdos formativos.

\section{ASPECTOS METODOLÓGICOS E ANÁLISE DE RESULTADOS DA PESQUISA}

Para compreender como as questões estão postas na forma de desafios na reformulação dos cursos de licenciatura, realizamos uma pesquisa com professores e coordenadores de colegiados dos cursos de Pedagogia em três IES da Bahia, sendo duas públicas, e uma privada. São elas: Universidade Estadual de Santa Cruz (UESC); Universidade Estadual do Sudoeste da Bahia (UESB) e Faculdade Maurício de Nassau. 
A UESB está organizada em três campus (Vitória da Conquista, Jequié e Itapetinga) e possui 22 cursos de licenciatura. No seu projeto de recredenciamento (UESB, 2014) informa que trata-se de uma entidade autárquica, com sede administrativa e foro na cidade de Vitória da Conquista - Bahia. Vinculada à Secretaria da Educação do Estado da Bahia, é dotada de personalidade jurídica de direito público, com autonomia didático-científica, administrativa e de gestão financeira e patrimonial (art. $1^{\circ}$ da Lei 7.176/1997), em conformidade com as disposições da Constituição Federal e da Lei de Diretrizes e Bases da Educação Nacional (9.394/1996). O projeto de Pedagogia foi implantado nos três campus, de forma presencial, mas também na modalidades EaD e Plataforma Freire - Parfor. O processo de reconhecimento do curso informa que

a carga horária total para a integralização do Curso é de 3.205 horas, distribuídas em atividades acadêmicas obrigatórias e optativas. O discente dispõe de um rol de disciplinas que permitirão o direcionamento da sua formação, segundo seu perfil e interesses, devendo cumprir obrigatoriamente a carga horária exigida para a sua integralização. O Curso, em sua carga horária total, será integralizado em 8 (oito) semestres letivos. O aluno deve cursar 7 (sete) disciplinas optativas, com 60 (sessenta) horas, totalizando 420 (quatrocentos e vinte) horas (UESB, 2012, p. 53).2

A UESC foi instituída pelo governo da Bahia em 05 de dezembro de 1991, teve o seu credenciamento aprovado, através do Parecer n 089/99, do Conselho Estadual de Educação - CEE, publicado no D.O.E de 01 de junho de 1999, corroborado pelo Decreto Estadual n 7633, de 16 de julho de 1999, publicado no D.O.E de 17 e 18 de julho de 1999. Compreende as regiões de planejamento do Estado da Bahia: o Litoral Sul, que abrange um vasto espaço do território do estado, agregando as sub regiões conhecidas como Baixo-sul (11 municípios), Sul (42 municípios) e Extremo-sul (21 municípios) da Bahia. A UESC possui 11 cursos de licenciatura, dentre eles, o curso de Pedagogia presencial, e também as modalidades Parfor e EaD.

Já a instituição privada que pesquisamos, Faculdade Mauricio de Nassau, teve suas atividades iniciadas em Vitória da Conquista em outubro de 2014, oferecendo cursos de graduação a partir de 2015, em Administração, Secretariado Executivo, Relações Públicas, Ciência da Informação, Biblioteconomia, Filosofia e Psicologia. Porém, a pesquisa foi feita tão somente com a coordenação do curso de licenciatura em Pedagogia, campus de Vitória da Conquista, o qual foi iniciado na referida IES em 2016.

A nossa pesquisa foi qualitativa, de natureza exploratória, na qual de acordo Triviños (1987) são observados alguns aspectos:

$\left.1^{\circ}\right)$ A pesquisa qualitativa tem o ambiente natural como fonte direta dos dados e o pesquisador como instrumento-chave; $2^{\circ}$ ) A pesquisa qualitativa é descritiva; $3^{\circ}$ ) Os pesquisadores qualitativos estão preocupados com o processo e não simplesmente com os resultados e o produto; $4^{\circ}$ ) Os pesquisadores qualitativos tendem a analisar seus dados indutivamente; $5^{\circ}$ ) O significado é a preocupação essencial na abordagem qualitativa [...]. Encaminhamos um questionário de perguntas abertas para docentes e coordenadores dos cursos de Pedagogia das respectivas instituições

Como instrumentos de coleta de dados utilizamos entrevista semiestruturada, cujos questionamentos visaram contemplar questões sobre: 1) desafios encontrados para a reformulação dos cursos de licenciatura; 2) a aplicabilidade das mudanças propostas nas reformulações dos cursos; 3) a participação dos docentes no processo de reformulação; 4) possíveis avanços nas IES a partir da reformulação dos cursos; 5) impacto

2 Disponível em: Projeto de Reconhecimento de curso.http://www2.uesb.br/proreitorias/prograd/wp-content/uploads/doc_cursos/pedagogia_lic_vc_projeto_renovacao_reconhecimento.pdf. Acesso em: 11/04/2019. 
na prática pedagógica dos docentes; e 6) investimentos na formação continuada dos docentes das IES para melhorar o processo ensino-aprendizagem. Os dados serão apresentados sem identificação dos sujeitos. Destacamos apenas se o sujeito é de IES pública ou privada.

Dentre os principais desafios para a reformulação dos cursos de licenciatura, elencados pelos sujeitos pertencentes às IES públicas, destacam-se a falta de articulação entre os professores do curso de modo a constituir uma visão conjunta e consensuada sobre formação de professores no geral, e sobre formação de professores para uma área específica. Há, também, uma falta de motivação generalizada por parte de estudantes em relação a ser professor, sobretudo no que se refere às expectativas sobre a carreira e as questões relativas a condições salariais da profissão. E, ainda, é preciso considerar a grande quantidade de estudantes sem condições financeiras que não Ihes permitem dedicar tempo suficiente para os estudos da área e, do mesmo modo, não lhes permitem ter outras vivências culturais mais amplas, que transcendem o conteúdo específico da formação de professores e atingir outras experiências como viagens, visitas a museus, teatro etc. o que por sua vez, repercutem no processo de formação. Outro aspecto observado foi que as mudanças do capitalismo global que repercutem nas políticas educacionais, fazem com que a educação superior passe por várias reformulações para adequar às exigências mercadológicas. E, por isso, as reformulações empreendidas por qualquer IES obedece a diretrizes que partem das políticas internacionais, materializando-se, por sua vez em documentos (resoluções, leis, subsidiadas por pareceres advindos do CNE) que embasam as reformulações necessárias aos cursos e as quais as IES são submetidas. Nessa perspectiva, de acordo com um dos sujeitos investigados,

[...] por não termos um projeto de educação nacional tampouco das nossas universidades a esse fim, essas reformulações sempre são pautadas a partir das decisões dos especialistas (naquele momento político) do MEC, em conformidade com o pseudoprojeto elaborado pelo partido que está no governo. Nesse aspecto, apesar de muito termos avançado no campo educacional, não sabemos para onde ir, uma vez que esses partidos não formularam/não formulam um projeto de educação para o país, ao contrário, esses partidos, essas pessoas tomam decisões para responder a determinada imposição de agentes internacionais, dos organismos multilaterais, dentre outros. Assim, não há de forma clara e precisa a meta, o objetivo que queremos atingir, pois nos falta um projeto. As ações, as estratégias que deveriam fazer parte desse projeto, não poderiam sofrer modificações abruptas diante das mudanças de governo. Ora, tudo isso não é novo, já é sabido, é dito e redito, mas como dizia Milton Santos, o Brasil nunca teve um projeto nacional, desse modo, vivemos nas nossas instituições, nos nossos cursos as angustias e agruras emanadas dessa ausência (Docente da IES pública).

Porém, para o sujeito da IES privada os desafios forma identificados da seguinte forma:

\footnotetext{
"Considerando que nas instituições de ensino superior da iniciativa privada, a maior parte dos docentes são horistas, os desafios são: Conseguir realizar as várias reuniões com o maior número possível de docentes, falta de tempo e de conhecimento de documentos oficiais e fundamentação teórica, necessários para desenvolver a proposta" (Docente da IES privada).
}

Sobre a implementação das mudanças propostas nas reformulações, os sujeitos das instituições púbicas mencionaram que no geral, atingem mais o nível do documento do que o nível da prática formativa em si. Nem todos os docente dos cursos acompanham as discussões sobre a reformulação e os aspectos conceituais que circundam os processos de mudança curricular. Desse modo, grande parte desses docentes permanecem lecionando os mesmos conteúdos, as mesmas proposta metodológicas, pois não participam 
e nem absorvem os resultados das reformulações. Outro aspecto apontado foi que as IES devem se concentrar nas necessidades educativas da educação básica para fazer a formação inicial. Como sugestão apontam que após a submissão da Proposta Pedagógica Curricular ao Conselho Superior de Ensino, Pesquisa e Extensão - CONSEPE, por sua vez, antes de ir a plenária deste Conselho, é enviada à Câmara de Graduação, que analisará a proposta e emitirá um parecer. Nessa etapa, a sugestão é que a análise realizada deve ser minuciosa, rígida, que possa ser avaliada para além dos aspectos administrativos, do impacto ao orçamento. Os/as coordenadores/as devem ser chamados a discuti-la na sua inteireza de acordo com os objetivos e responsabilidades da instituição para com a formação inicial e, para além do que é propugnado pelo MEC, que desconhece o contexto social, econômico, histórico da instituição e do seu alunado. Nesse sentido, um dos sujeitos, coordenador do colegiado de Pedagogia de uma instituição pública salienta:

No caso do PPC da Pedagogia [...] não fizemos o nosso mea culpa por nossa participação na taxa de crescimento exponencial de alfabetismo funcional entre crianças, jovens e adultos, do analfabetismo das crianças, que conduz a crianças bi-repetentes, tri-repetentes, até o momento dela sair da escola, ou de se pensar como incapaz de aprender, dentre outros. O curso de Pedagogia, deveria ser pensado e organizado para além das disciplinas, para além da matriz curricular necessária ao pedagogo. Pensamos no processo de reformulação, nas disciplinas, na carga horária destas, que estejam em consonância com as diretrizes para a formação inicial, quais disciplinas serei responsável, mas não pensamos se esse profissional domina as competências básicas (infelizmente ainda perecemos) para atuar na educação infantil e nos anos iniciais do ensino fundamental. Será que esse/a egresso/a será capaz de alfabetizar? Será que domina os conceitos básicos da geografia, da matemática, das ciências para poder ensinar? E, assim, por diante. O resultado dessa lacuna, está sendo apresentado gradativamente pelo MEC, pelos empresários da educação, para esses o pedagogo ficará restrito à educação infantil e aos $1^{\circ}$ e $2^{\circ}$ anos. Para os demais anos de escolarização, virão o licenciado em geografia, matemática, etc. Dessa forma, nosso campo de atuação se tornará restrito.

Para os sujeitos da IES privada, as mudanças propostas na reformulação do curso têm sido materializadas apenas na representação estudantil de líderes de salas e não de colegiados, além de iniciação a programas de pesquisa.

Sobre a participação na reformulação dos cursos, a maioria dos sujeitos investigados nas IES públicas participaram de forma ativa, desde a discussão sobre o nível conceitual atingido pela reformação até as proposições de disciplinas, ementas, metodologias e referências bibliográficas. Um dos docentes salienta que houve inclusive a participação de estudantes.

Participei de uma comissão de reformulação do projeto de curso de pedagogia na UESB - Itapetinga, houve inicialmente seminários com os estudantes para ouvir ideias das prioridades de mudanças no currículo em vigência, reuniões com todos os professore do curso com o mesmo propósito e, em seguida, várias reuniões da comissão de reforma para discussão e elaboração do novo projeto. Alguns atritos provocados por comportamentos mais autoritários, consequência da nossa pouca experiência em processos democráticos, porém controlados por colegas mais experientes e com perfil de coordenação.

Sobre essa questão todos os sujeitos da IES privada informaram que não participaram do processo de reformulação. Outro aspecto questionado na pesquisa foi sobre possíveis avanços nos cursos de licenciatura após a reformulação. Para esta questão os sujeitos das IES públicas nos informaram que apesar de se perceber ainda muito continuísmo na prática de alguns docentes, também pode-se observar algumas mudanças, pois há professores que vivem mesmo a reformulação ao nível da concepção e, desse modo, não ficam alheios 
às mudanças porque as querem na prática. Em geral, as mudanças que ocorrem são fruto de lutas em prol da inserção ou para a atualização de algumas temáticas no currículo das licenciaturas, a exemplo de inclusão em geral, educação do campo, políticas educacionais etc. Especificamente, no curso de Pedagogia, consideram que houve avanços significativos, tais como: a adoção do Trabalho de Conclusão de Curso - TCC e da Atividades Acadêmicas Científicas Culturais - AACC. Acreditam que com o TCC os/as estudantes passaram a perceber a pesquisa, a buscarem inserção dos projeto de pesquisa por meio da Iniciação Científica - IC. No que concerne a AACC, verificam a preocupação dos/as estudantes em participar dos eventos realizados na universidade. Porém, um dos sujeitos levantou alguns pontos para ser refletidos sobre essa questão:

Considero que houve alguns avanços, porém, a ausência de especialistas em currículos, até mesmo a ausência de pedagogos em várias etapas da reformulação dos cursos, trazem consequências que prejudicam os resultados. Em alguns cursos o processo de reformulação avança para uma concepção mais holística ou interdisciplinar, tentando superar a visão fragmentada que ainda impera em nossos currículos e em nossas práticas (Docente da IES pública).

Ainda sobre essa questão dos avanços após a reformulação dos cursos, os sujeitos da IES privada se limitaram a dizer que "os avanços foram muito pouco desde 2012 até os dias atuais. Os docentes do nosso colegiado são atentos e antenados com a proposta do PPC e com a prática pedagógica, pois são pesquisadores e têm efetivo interesse com a qualidade do curso." Realizamos questões sobre as possíveis melhorias no processo ensino-aprendizagem das instituições depois da reformulação dos cursos de licenciatura, e a partir das respostas percebemos que as melhoras tímidas são percebidas, se olhados os cursos como um todo. Ressaltam que a presença de algumas temáticas fruto das discussões mais contemporâneas é um elemento que demarca um perfil de formação docente mais antenado com as discussões atuais da área. No entanto, há ainda muito o que se precisa atualizar. Um destaque mencionado foi sobre o projeto acadêmico atual do curso de pedagogia da UESC que traz várias disciplinas denominadas Atividade Integradora Baseada em Problema - AIBP I, II, III, IV, V, VI e VII. Sobre estas, um docente a referida IES salienta:

Alguns colegas questionam a necessidade de tantas, tenho trabalhado com a I e II, exatamente no primeiro e segundo semestres letivos. Estas disciplinas exigiram novas pesquisas, onde procurei atuar provocando na turma uma leitura do projeto do curso, do papel do pedagogo dentro e fora dos espaços escolares. A importância das disciplinas que eles cursam neste semestre letivo, através de análise das ementas.

Um fator importante analisado sobre a reformulação dos cursos de licenciatura foi quanto ao interesse de alunos com potencial cultural para desenvolverem bons percursos formativos. Sobre essa questão, as IES públicas pesquisadas evidenciaram que a pouca valorização da carreira docente tem sido um grande problema pois não incentiva os jovens a ingressar nos cursos de licenciatura. Há uma incidência de estudantes que estão num curso de licenciatura porque não conseguiram adentrar em outros cursos cujas carreiras profissionais valorizam mais os trabalhadores. Porém, não podemos desconsiderar outras variáveis nesse contexto, que são para além da valorização da carreira docente, tais como: "o percurso desse estudante na educação básica; o projeto de vida desse estudante, quer dizer, o que lhe movimentou para a escolha; o contexto sócio, econômico desse aluno, dentre outros que estão relacionados a estes" (Docente da IES pública). Essa questão foi respondida também pelos sujeitos da IES privada, cuja resposta foi que isso pode ser verificado

“[...] quando vemos o envolvimento dos acadêmicos nas atividades que a instituição realiza para cumprimento da resolução; Percebo que esse fenômeno ocorre em espaços formativos da iniciativa privada. A justificativa de inúmeros alunos para a escolha pelo bacharelado segue esse viés. Inclusive, fazem vestibular para a licenciatura e depois solicita a troca para outro curso." (Docente da IES privada). 
Dentre os principais desafios para dar aulas em cursos de licenciatura atualmente registrados pelas IES públicas foram destacados: alunos sem tempo para estudo; alunos com pouco acúmulo de conhecimento geral da experiência de educação básica; alunos desmotivados porque pretendiam cursas outra formação em nível superior; alunos sem muita expectativa em relação à profissão docente; alunos que trabalham e sempre perdem parte das aulas; alunos que ingressam nas licenciaturas, muitos com dificuldades de leitura e interpretação de textos; a frequência e pontualidade dos alunos prejudicadas pelos problemas de deslocamentos das suas cidades de origem para a Universidade e vice-versa; a falta de afinidade de muitos alunos com o curso, pela forma de acesso, pois nem sempre foi o curso que ele escolheu como primeira opção, mas foi o curso possível pela sua pontuação no Exame Nacional do Ensino Médio - ENEM.

Sobre estes desafios, as respostas dadas pelos sujeitos da IES privada seguem a mesma perspectiva, pois destacam que o professor deve ter a capacidade de envolver os alunos no mundo da academia como pesquisadores, constituir-se como mediador orientando os acadêmicos para a participação em congressos, simpósios, seminários e a publicarem as suas pesquisas. E destacam que a instituição conta com discentes sem as habilidades e competências referentes ao ensino fundamental e médio; a falta de crença de sucesso na profissão; a experiência discente que os futuros professores tiveram na escola; além das mudanças constantes de parâmetros, diretrizes, sistemas de avaliação e políticas nacionais da formação docente.

Para que realmente haja melhorias na aprendizagem dos cursos de formação de professores, necessário se faz pensar também na formação continuada dos docentes das IES, os quais têm que realizar pesquisas e extensão continuamente, para que possam produzir novos conhecimentos de acordo com as mudanças da sociedade. Nesse sentido, ao investigarmos sobre os investimentos das IES para a qualificação dos docentes, obtivemos as seguintes respostas nas instituições públicas:

No nosso caso de docente da educação superior e como outros, certamente será o profissional que planejará a continuidade da sua formação. A UESC e as demais universidades baianas estão em um momento político, econômico fragilizado pelas medidas do governo do estado e do país, assim, o/a docente faz a sua solicitação e espera que seja atendido...não há certezas...Porém, existem algumas medidas que foram tomadas por determinados departamentos e, apoiados, pela administração central em criar condições para que alguns convênios (DINTER/MINTER) interinstitucionais fossem firmados, em atendimento a demandas de docentes que ainda não haviam realizado o mestrado e ou o doutorado.

A UESB proporciona liberação para que os docentes possam se qualificar, sejam em nível de mestrado, doutorado ou mesmo pós-doutorado. Atualmente está mais difícil essa liberação por falta das condições de ter um professor substituto, mas os próprios colegas professores se organizam para garantir a qualificação de todos:

Vários eventos são desenvolvidos dentro da UESC, frutos dos programas de pós-graduação e dos projetos de pesquisa e extensão, além da possibilidade de participar em eventos de outras instituições. Porém, as dificuldades de participação vêm da carga horária dos professores que além da sala de aula desenvolvem atividades de orientação de alunos, projetos de pesquisa, extensão etc.

Os dados sobre esta última questão demonstram que as universidades públicas fazem os investimentos para a formação de docentes, conforme preconiza o Plano Nacional de Educação na Meta 13.9: “Elevar a qualidade da educação superior e ampliar a proporção de mestres e doutores do corpo docente em efetivo 
exercício no conjunto do sistema de educação superior para 75\% (setenta e cinco por cento), sendo, do total, no mínimo, 35\% (trinta e cinco por cento) doutores" (BRASIL, 2014). Mesmo que ainda seja insuficiente, e que em alguns casos sejam os próprios professores que assumem a carga horária dos colegas para que estes possam se qualificar, ainda assim, percebe-se um maior investimento na rede pública do que na rede privada, pois de acordo com os sujeitos, na instituição privada pesquisada, "Não há estímulo para a formação continuada strictu sensu, haja vista que não há redução de carga horária ou liberação do professor. No máximo, ajuste no horário para que ele possa frequentar as aulas. Oferece apenas cursos de especialização com baixíssimo custo para o professor".

Vale ressaltar que a formação para professores da educação básica no Brasil, é feita em todos os cursos de licenciatura, e que todas estas passaram ou estão passando por processos de reformulação, em atendimento à legislação educacional vigente. Assim, necessário se faz a melhoria da qualidade da formação desses profissionais, tão importante para o país, de modo que possa ser garantida uma educação básica com melhores oportunidades formativas para as futuras gerações. 


\section{CONSIDERAÇÕES FINAIS}

A interação dos diferentes fatores aqui levantados como desafios para a reformulação dos cursos de licenciatura nas IES investigadas apontam que as condições institucionais dos cursos de formação de docentes para a educação básica nos sinaliza um cenário preocupante sobre as atividades formativas. Isto nos reporta que a formação deve levar em consideração a função social própria à escolarização - ensinar às novas gerações de acadêmicos o conhecimento acumulado e consolidar valores e práticas coerentes com nossa vida civil, no que concerne a proposição de um modelo de sociedade menos desigual e mais justo.

Isto posto, concluímos que a formação de professores para atuarem na educação básica tem que partir de seu campo de prática e agregar a este os conhecimentos teóricos necessários para fazer a integração teoria-prática, observando os fundamentos e com as mediações didáticas necessárias para fazer uma educação que tenha uma base sólida e com conhecimentos científicos para compreender e transformar o entorno social. 


\section{REFERÊNCIAS}

ARELARO, Lisete Regina Gomes. Formulação e implementação das políticas públicas em educação e as parcerias público-privadas: impasse democrático ou mistificação política? Revista Educação e Sociedade, Campinas, vol. 28, n. 100 - Especial, p. 899-919, out. 2007.

BARÃO, Gilcilene de Oliveira Damasceno. O Plano de Desenvolvimento da Educação (PDE): uma política educacional do capital. Boletim Germinal - Grupo de Estudos e Pesquisas Marxismo, História, Tempo Livre e Educação, n 9, nov. 2009.

BRASIL. Constituição Federal do Brasil de 1988. Brasília, 1988.

BRASIL. Lei de Diretrizes e Bases da Educação Nacional. Lei Federal n 9.394/96. Brasília: Congresso Nacional, 1996a.

BRASIL. Emenda Constitucional no 14, de 12 de setembro de 1996. Modifica os Artigos 34, 208, 211 e 212 da Constituição Federal e dá nova redação ao artigo 60 do Ato das Disposições Constitucionais Transitórias. Brasília, 1996b.

BRASIL. Emenda Constitucional n 53, de 19 de dezembro de 2006. Dá nova redação aos Arts. $7^{\circ}, 23,30$, 206, 208, 211 e 212 da Constituição Federal e ao Art. 60 do Ato das Disposições Constitucionais Transitórias. Brasília, 2006.

BRASIL. O Plano de Desenvolvimento da Educação: análise do projeto do MEC. Revista Educação e Sociedade, Out 2007, vol. 28, n 100, p.1231-1255.

BRASIL. Ministério da Educação. Decreto $n^{\circ}$ 6.755, de 29 de janeiro de 2009. Institui a Política Nacional de Formação de Profissionais do Magistério da Educação Básica, disciplina a atuação da Coordenação de Aperfeiçoamento de Pessoal de Nível Superior-CAPES no fomento a programas de formação inicial e continuada, e dá outras providências. Brasília, 2009.

BRASIL. Lei no 13.005, de 25 de junho de 2014. Aprova o Plano Nacional de Educação - PNE e dá outras providências. Diário Oficial da União de 25 de junho de 2014. Brasília, 2014.

BRASIL. Parecer CNE/CP $n^{\circ}$ 2, aprovado em 9 de junho de 2015. Diretrizes Curriculares Nacionais para a Formação Inicial e Continuada dos Profissionais do Magistério da Educação Básica. Brasília, 2015a.

BRASIL. Resolução $n^{\circ} 2$, de $1^{\circ}$ e julho de 2015. Define as Diretrizes Curriculares Nacionais para a formação inicial em nível superior (cursos de licenciatura, cursos de formação pedagógica para graduados e cursos de segunda licenciatura) e para a formação continuada. Brasília, 2015b.

BRASIL. Decreto $n^{\circ}$ 8.752, de 9 de maio de 2016. Dispõe sobre a Política Nacional de Formação dos Profissionais da Educação Básica. Presidência da República Básica. Presidência da República. Casa Civil. Subchefia para Assuntos Jurídicos, 2016a. Disponível em: http://www.planalto.gov.br/ccivil_03/_Ato2015-2018/2016/Decreto/ D8752.htm. Acesso em: 25 abr. 2017. 
CARDOSO, Elisângela Andrade Moreira; NUNES, Cláudio Pinto. O Plano Nacional de Formação de Professores da Educação Básica (PARFOR): o ideal e a realidade vigente. Educação \& Formação, Fortaleza, v. 2, n. 6, p. 54-69, set./dez. 2017.

DOURADO, Luiz Fernandes. Diretrizes Curriculares Nacionais para a Formação Inicial e Continuada dos Profissionais do Magistério da Educação Básica: concepções e desafios. Educação e Sociedade, Campinas, v. $36, n^{\circ} .131$, p. 299-324, abr.-jun. 2015.

FREITAS, Helena Costa Lopes de. A (nova) Política de formação de professores: a prioridade postergada. Educação e Sociedade, Campinas, n 100 - Especiais, p. 1203-1230, out. 2007. Disponível em: http://www. cedes.unicamp.br. Acesso em: 15 jan. 2018.

GATTI, Bernadete A. Formação de professores no Brasil: Características e problemas. Educ. Soc., Campinas, v. 31, n. 113, p. 1355-1379, out-dez. 2010. Disponível em: Disponível em: http://www.scielo.br/pdf/es/ v31n113/16.pdf

INEP. Censo da Educação Básica: resumo técnico. Brasília: INEP, 2015a. Disponível em: www.inep.gov.br/ educacao_basica/censo_escolar/resumos_tecnicos. Acesso em: 01 jul. 2017.

INEP. Censo da Educação Superior 2015. Brasília, DF: MEC/INEP, 2015b. Disponível em: http://www.inep. gov.br/basica/censo/default.asp . Acesso em: 25 jul. 2017.

LIBÂNEO, José Carlos; PIMENTA, Selma Garrido. Formação de profissionais da educação: visão crítica e perspectiva de mudança. In: Educação e Sociedade. [online]. vol. 20, n 68, p. 239-277, 1999. ISSN 0101-7330. Disponível em: http://www.scielo.br/scielo.php?script=sci_pdf\&pid=S0101-73301999000300013\&lng=en\&n rm=iso\&tlng=pt. Acesso em: 13 ago. 2017.

MARX, Karl; ENGELS, Friedrich. Manifesto do Partido Comunista. Tradução Pietro Nassetti. São Paulo: Martin Claret, 1981.

MÉSZÁROS, István. O poder da ideologia. Tradução Magda Lopes e Paulo Cezar Castanheira. 1 ed. 5 reimpr. São Paulo: Boitempo, 2014.

OLIVEIRA, Dalila Andrade. Mudanças na Organização e na Gestão do Trabalho na Escola. In: OLIVEIRA, Dalila Andrade; ROSAR, Maria de Fátima Felix. (Org.). Política e Gestão da Educação. Belo Horizonte: Autêntica, 2002.

PEREIRA, Potyara Amazoneida Pereira. Política social: temas e questões. São Paulo: Cortez, 2008.

SANTOS, Arlete Ramos dos; CARDOSO, Elisângela Andrade Moreira. As Políticas Públicas Educacionais do PAR para a Formação do Professor do Campo em Vitória da Conquista/BA. Revista Prâksis. Novo Hamburgo, a. 14, v. 1, jan./jun. 2017.

SANTOS, Arlete Ramos dos; OLIVEIRA, Niltânia Brito; CARDOSO, Elisângela Andrade Moreira. O Plano de Ações Articuladas em Escolas do Campo na Bahia. In: Anais... III Seminário Internacional de Educação do Campo e III Fórum de Educação do Campo da Região Norte do Rio Grande do Sul: Resistência e Emancipação Social e Humana, Erechim/RS, 29, 30 e 31 de Mar. 2017. 
SAVIANI, Dermeval. Trabalho e Educação: fundamentos ontológicos e históricos. In: Trabalho encomendado pelo GT - Trabalho e Educação. Anais... 29ª Reunião da ANPEd no dia 17 de outubro de 2006, em Caxambu.

SAVIANI, Dermeval. O Plano de Desenvolvimento da Educação: análise do projeto do MEC. Educação e Sociedade, Out 2007, vol. 28, nº 100, p.1231-1255.

SILVA, Marcelo Silva da; SANFELICE, Gustavo Roese. Profissionalização docente e as políticas públicas no campo da formação. Revista Prâksis, [S.I.], v. 2, p. 31-38, aug. 2008. ISSN 2448-1939. Disponível em: http:// periodicos.feevale.br/seer/index.php/revistapraksis/article/view/649. Acesso em: 04 mar. 2017.

TRIVIÑOS, Augusto Nibaldo Silva. Três enfoques na pesquisa em ciências sociais: o positivismo, a fenomenologia e o marxismo. In: Introdução à pesquisa em ciências sociais. São Paulo: Atlas, 1987. p. 31-79.

SANTOS, A. R.; CARDOSO, E. A. M.; NUNES, C. P.

Reformulação de cursos de licenciatura na Bahia: interesses e desafios subjacentes

Formação Docente - Revista Brasileira de Pesquisa sobre Formação de Professores Vol. 11, n. 21 (p. 11-30) 30 ago. 2019 
